\title{
DO PODER DISCIPLINAR AO BIOPODER: MEDICALIZAÇÃO DO PARTO A PARTIR DA INCIDÊNCIA DE CESARIANẢS
}

\author{
Maiane Cibele de Mesquita Serra* \\ Glaucia Fernanda Oliveira Martins Batalha*
}

\section{RESUMO}

A violência obstétrica caracteriza-se como uma violência institucional e de gênero, uma vez que há utilização arbitrária do saber por parte de profissionais da saúde no controle dos corpos e da sexualidade das parturientes. Objetiva-se analisar sob esse viés as cesáreas eletivas, propondo uma reflexão sobre o processo de medicalização do parto, analisando tais questões, a partir dos conceitos de poder, poder disciplinar, biopoder e biopolítica, propostos por Michel Foucault. A pesquisa é de caráter bibliográfico, respaldada a partir da análise e interpretação de livros e artigos científicos, subsidiada também pelos depoimentos de mulheres que sofreram violações.

Palavras-chave: Violência obstétrica. Cesárea eletiva. Poder disciplinar. Biopoder. Biopolítica.

\section{DISCIPLINARY POWER TO BIOPOWER: MEDICALIZATION OF CHILDBIRTH FROM INCIDENCE OF CESAREAN}

\begin{abstract}
Obstetric violence is characterized as institutional and gender violence, since there is arbitrary use of knowledge by health professionals to control the bodies and sexuality of parturients. The objective is to analyze under this bias the elective cesareans, proposing a reflection on the medicalization of childbirth process, analyzing these issues, based on the concepts of power, disciplinary power, biopower and biopolitics, proposed by Michel Foucault. The research is bibliographic, supported by the analysis and interpretation of books and scientific papers, also supported by the testimonies of women who suffered violations.
\end{abstract}

Keywords: Obstetric violence. Elective cesarean. Disciplinary power. Biopower. Biopolitics.

\section{INTRODUÇÃO}

A Organização Mundial de Saúde (OMS, 2002) define violência como a imposição

\footnotetext{
Mestre em Direito e Instituições do Sistema de Justiça pela Universidade Federal do Maranhão (PPGDIR/UFMA). Especialista em Docência na Educação Profissional e Tecnológica pelo SENAI CETIQT RJ. Bacharel em Direito. Licenciada em Letras - Português e Inglês. Pós-graduanda em Processo Civil. Foi bolsista CAPES. Advogada pela OAB/MA. Professora da Faculdade Santa Terezinha - CEST e Faculdade Laboro. E mail: maianeserra@hotmail.com. Currículo Lattes: http://lattes.cnpq.br/5010030376540550. ID ORCID: http://orcid.org/0000-0002-0112-4465

Mestre em Direitos Humanos pela Universidade Federal do Pará- UFPA. Pós-graduada em Direito Administrativo e Administração Pública pela Universidade da Amazônia- UNAMA. Advogada pela OAB/MA. Professora e Coordenadora do Curso de Direito e Professora da Faculdade Santa Terezinha - CEST. Currículo Lattes: http://lattes.cnpq.br/1051668391621795. E mail: glauciaf_martins@yahoo.com.br. ID ORCID: http://orcid.org/0000-0002-0458-0319
} 
de um grau significativo de dor e sofrimento evitáveis. Por sua vez, a violência contra a mulher é definida pela Convenção Interamericana para Prevenir, Punir e Erradicar a Violência contra a Mulher, também conhecida como "Convenção de Belém do Pará", no seu art. $1^{\circ}$ como: "qualquer ato ou conduta baseada no gênero, que cause morte, dano ou sofrimento físico, sexual ou psicológico à mulher, tanto na esfera pública como na esfera privada" (1994, p. 1). E no art. $6^{\circ}$ determina que o direito de toda mulher a ser livre de violência, abrange, entre outros, o direito a ser livre de todas as formas de discriminação, além do direito de ser valorizada e educada livre de padrões estereotipados de comportamento e costumes sociais e culturais baseados em conceitos de inferioridade ou subordinação.

A violência contra a mulher consiste em uma das principais formas de violação dos direitos humanos, estando presente em uma realidade lamentável na maioria das sociedades. Inserida no contexto da violência contra a mulher está a violência obstétrica ou violência na atenção obstétrica, caracterizada pela apropriação do corpo e dos processos reprodutivos da mulher pelos agentes de saúde, mediante um tratamento desumanizado, abuso de medicalização e patologização dos processos naturais, causando a perda de autonomia da parturiente e da sua capacidade de decidir livremente sobre seu corpo e sexualidade, o que pode culminar em consequências negativas e desastrosas para a qualidade de vida das mulheres.

Tal violação constitui-se também como uma violência de gênero, perpetuando-se de forma física, verbal, sexual e psicológica ocorridas tanto no âmbito privado quanto público podendo ser perpetradas inclusive pelo Estado e seus agentes, manifestadas através das relações de poder, histórica e culturalmente desiguais ocorridas entre homens e mulheres ${ }^{1}$.

Em 2000, 191 países membros das Nações Unidas adotaram a Declaração do Milênio, assumindo oito compromissos que, se cumpridos, possuíam o condão de melhorar a qualidade de vida da humanidade. O Brasil é signatário dessa declaração, quando na ocasião todos os países presentes se comprometeram em reduzir em dois terços a mortalidade de crianças menores de 5 anos (meta 5) e reduzir em três quartos, a taxa de mortalidade materna

\footnotetext{
${ }^{1}$ Definição dada pelas leis venezuelana e argentina, onde a violência obstétrica é tipificada: Lei Orgânica sobre o Direito das Mulheres a uma Vida Livre de Violência, de novembro de 2007 vigente na Venezuela e Lei Nacional $\mathrm{n}^{\circ}$ 26.485, de Proteção Integral para Prevenir, Punir e Erradicar a Violência contra as Mulheres nos Âmbitos em que se Desenvolvem suas Relações Interpessoais, vigente na Argentina desde 2009.
} 
(meta 6) (BRASIL, 2004). Entretanto, fatores associados à violência obstétrica impedem que tais metas sejam alcançadas, tendo em vista os altos índices de mortalidade materna e neonatal no país ${ }^{2}$, impossibilitando o Brasil quanto ao cumprimento do compromisso internacional assumido (SOUSA, 2015).

Em distintas partes do mundo, essa modalidade de violência tem se alastrado de maneira preocupante e silenciosa, haja vista que as mulheres vítimas desta prática não a percebem como tal. Culturalmente, o parto ainda é percebido e significado como um momento de "dor necessária". Em algumas situações, quando a parturiente se dá conta da violência praticada contra ela, opta pelo silêncio, muitas vezes pelo medo de ser abandonada pelo profissional em um momento onde está altamente vulnerável ou ainda por não se sentir apoiada quanto à denúncia. Outros fatores também corroboram para que a mulher violentada não denuncie a prática, a saber, crer que não possui provas suficientes do ato de violência sofrido; desacreditar na justiça e ainda por desconhecer as atitudes que se configuram como violência obstétrica (PAES, 2015).

A partir de uma metodologia, de caráter exploratório, do tipo qualitativo, envolvendo pesquisa bibliográfica, respaldada a partir da análise e interpretação de livros e artigos científicos, sendo subsidiada também pelos depoimentos de mulheres que sofreram violações, este estudo se propõe a analisar as questões voltadas para a medicalização do parto a partir da incidência de cirurgias cesarianas, objetivando refletir sobre essas ponderações a partir de conceitos propostos pelo filósofo francês Michel Foucault (19261984) para a construção do poder como mecanismo que se desenvolve a partir das relações sociais, analisando-se, para isso, noções sobre o poder disciplinar, biopoder e biopolítica.

\section{DO PODER DISCIPLINAR AO BIOPODER: MEDICALIZAÇÃO DO PARTO A PARTIR DA INCIDÊNCIA DE CESARIANAS}

A noção de poder em Foucault encontra-se deslocada da ideia de poder monopolizada pelo Estado, sendo direcionada a partir de relações sociais através de uma rede de "micro-poderes". Nesse sentido, esse poder seria analisado a partir das periferias para se ter noção da sua real dimensão em todas as estruturas sociais. Sob essa perspectiva Foucault preleciona que:

\footnotetext{
${ }^{2}$ A taxa de mortalidade neonatal no país está em 11,1 por mil nascidos vivos e a taxa de mortalidade materna é de aproximadamente 61 mulheres por cem mil nascidos vivos (LEAL et al., 2012).
} 
[...] em primeiro lugar: não se trata de analisar as formas regulamentares e legítimas do poder em seu centro, no que possam ser seus mecanismos gerais e seus efeitos constantes. Trata-se, ao contrário, de captar o poder em suas extremidades, lá onde ele se torna capilar; captar o poder nas suas formas e instituições mais regionais e locais, principalmente no ponto em que, ultrapassando as regras de direito que o organizam e delimitam, ele se prolonga, penetra em instituições, corporifica-se em técnicas e se mune de instrumentos de intervenção material, eventualmente violento (FOUCAULT, 2008, p. 182).

A preocupação de Foucault é analisar esse poder a partir do seu nível molecular (MACHADO, 2009). Nesse sentido, Foucault faz a sua análise observando justamente as instituições (hospitais, hospícios, fábricas, escolas, entre outros) que vão ajudar a compreender como essas relações de poder são formadas. E, nesse sentido, o filósofo expressa que "o poder está em toda parte; não porque englobe tudo, e sim porque provém de todos os lugares" (FOUCAULT, 2009, p. 89).

Essa análise microfísica do poder parte da ideia de que não é no Estado que se encontra a origem de todo o poder social, ele não é necessariamente o ponto de partida para a origem do poder [...] Esta análise se destaca justamente por afirmar que os poderes não estão localizados em um lugar específico da sociedade, mas estão distribuídos como uma rede de mecanismos que não escaparam a ninguém em toda a estrutura da sociedade. (DINIZ; OLIVEIRA, 2014, p. 147)

Nesse aspecto, o poder não emana especificamente de um lugar ou instituição, mas apresenta-se através de discursos e práticas que atravessam permanentemente indivíduos e objetos (CHAZAN, 2007). Assim, Foucault examina os agentes de dominação nos núcleos mais elementares da sociedade ${ }^{3}$ para compreender tais relações.

O termo "biopolítico", formulado por Foucault, refere-se justamente aos diferentes modos sobre os quais esse poder se configura e se exerce ao longo da História.

A partir da formação dos Estados modernos associado a consolidação do capitalismo, surge uma nova concepção do significado de riqueza e a necessidade da sua mensuração através dos meios de produção. Nesse sentido, como forma de gerenciamento dessa riqueza, emergiu o conceito de população como uma ferramenta para a ciência do Estado, modificando-se ainda o exercício do poder. Havia, portanto, a necessidade de regular e disciplinar corpos, e, esse modo do exercício de poder, presente em todos os discursos, relações e práticas sociais, é designado por Foucault como poder disciplinar ou biopoder. O Estado passa então a se ocupar com a saúde dos habitantes, ocupando a

\footnotetext{
${ }^{3}$ Esses núcleos elementares são, a exemplo, a família, a vizinhança, os pais, o médico etc.
} 
medicina um locus fundamental. (CHAZAN, 2007).

Este instrumento de poder que atua no corpo dos homens usará a punição e a vigilância como principais mecanismos para adestrar e docilizar o sujeito, pois é a partir deles que o homem se adequará às normas estabelecidas nas instituições como um processo de produção que, a partir de uma "tecnologia" disciplinar do corpo, construirá um sujeito com utilidade e docilidade. (DINIZ; OLIVEIRA, 2014, p. 150, grifo nosso)

Nesse aspecto, a disciplina sob a lógica foucaultiana tem seu marco histórico na medida em que surge com ela a arte do corpo humano (Foucault, 2010). Através de uma política de coerção, os gestos, comportamentos e outros elementos do corpo humano serão manipulados, inserindo-o em uma maquinaria do poder e adestrando o sujeito moderno em um processo lento e cauteloso. Não é de todo um processo de dominação, mas sim de introjeção, a partir do qual se moldará a pessoa em um processo de adestramento do indivíduo, chamado por Foucault de "fabricação de indivíduos máquina". (DINIZ; OLIVEIRA, 2014).

Analisando a obra "Panopticon" de Jerermy Bentham ${ }^{4}$, Foucault apresenta o panoptismo como fundamento para a criação de um dispositivo de poder e também de um controle social, baseado na vigilância e controle por meio da visibilidade e da localização dos corpos no espaço, construindo assim, uma sociedade disciplinar.

O panoptismo é um dos traços característicos da atual sociedade capitalista, através da qual os indivíduos são vigiados, punidos, recompensados e normatizados. O efeito mais importante do panóptico é provocar, nos indivíduos, um estado consciente e constante de visibilidade que garante a manutenção automática do sistema de poder. A sociedade contemporânea é baseada em uma vigilância semelhante ao que acontecia com o sistema panóptico definido por Foucault. Assim, o princípio do panóptico continua plenamente ativo, mas agora se exerce nas novas formas de controle implementadas pelas novas tecnologias, trazendo consigo novas práticas e relações de poder. (MARINHO; REIS, 2014, p. $69)$.

O dispositivo de poder por meio do "panopticon" tornou-se indispensável e sua aplicação ampliou-se para outros setores da sociedade, tais como, escolas, hospitais, fábricas, e demais instituições nas quais o controle era necessário, disciplinando condutas,

\footnotetext{
${ }^{4}$ O Panóptico é uma prisão cuja arquitetura é da seguinte forma: ao redor de uma torre cheia de janelas é construído um conjunto de celas em forma de anel que terão as janelas da torre direcionadas para a parte interna desse anel. Cada cela terá duas janelas, uma na parte externa e outra na parte interna do anel, que será correspondente às janelas da torre. Isso será necessário para que a luz que atravessa a cela chegue até a torre e então é só colocar um vigia na torre central que ele terá uma visão privilegiada do sujeito que está sendo vigiado. (FOUCAULT, 2010. p. 190)
} 
determinando comportamentos e manipulando os corpos.

Para Agamben (2015) a noção de disposto repousa na ideia de capturar, orientar, determinar, interceptar, modelar, controlar práticas, gestos, condutas e opiniões. Para Kênia (2016, p. 21), “o dispositivo se liga a um conjunto de práticas que visam administrar, governar, controlar e orientar - de um modo que pretende ser útil - os comportamentos, gestos e pensamentos".

Desta forma, esse poder disciplinar, fruto das transformações da sociedade burguesa, garantiria o controle de todos os indivíduos que fazem parte de uma determinada sociedade, adestrando-os e transformando-os.

Complementando esse poder disciplinar, surge no século XVIII, um tipo de poder não mais voltado para o indivíduo em caráter particular, mas sim para a população, a qual Foucault intitula de "biopoder", responsável por controlar as massas, exsurgindo assim, um novo cenário: a biopolítica.

A biopolítica, nesse sentido, "carecerá de uma tecnologia que deve estar direcionada para dispositivos que devem assegurar a vida da população, pois sua meta é controlar aquilo que possa limitar a vida do homem não em particular, mas no conjunto da espécie humana." (DINIZ; OLIVEIRA, 2014, p. 154).

Assim, o biopoder funciona como ferramenta fundamental para essa nova tecnologia de poder, levando-se em conta os fenômenos coletivos. Para efetivar esse controle, será iniciada uma política de policiamento ${ }^{5}$, objetivando controlar as massas, sendo adotados vários procedimentos:

[...] uma medicina que vai ter, agora, a função maior de higiene pública, com organismos de coordenação dos tratamentos médicos, de centralização da informação, de normalização do saber, (...) de campanha de aprendizado da higiene e da medicalização da população. (FOUCAULT, 1999b, p. 291, grifo nosso).

Nesse aspecto, a medicina passa a exercer um papel fundamental no controle e gestão do corpo, interferindo nos modos de vida e nas condutas particulares e coletivas através da definição de regras que orientarão a vida moderna, não somente no que diz respeito à doença, mas também as questões comportamentais, sexualidade, fecundidade, fertilidade, natalidade, mortalidade, dentre outros (FOUCAULT, 2008). A esse respeito,

\footnotetext{
${ }^{5}$ Essa política de policiamento não refere-se ao controle no sentido militar, mas sim à vigilância como forma de controle populacional. (FOUCAULT, 2010).
} 
Foucault expressa que:

[...] a nova tecnologia que se instala se dirige à multiplicidade dos homens, não na medida em que eles se resumem em corpos, mas na medida em que ela forma, ao contrário, uma massa global, afetada por processos de conjunto que são próprios da vida, que são processos como o nascimento, a morte, a produção, a doença etc. (FOUCAULT, 1999b, p. 291).

Desta forma, a biopolítica preocupa-se com as relações entre a espécie humana e o meio em que ela vive (FOUCAULT, 1999b), criando mecanismos reguladores para preservar sua existência e manter o equilíbrio da população, operando-se um intenso processo de politização dos corpos, através do qual desenvolve-se a organização do poder sobre a vida. O poder, seria então uma forma de ação sobre a ação dos outros, exercendo-se através das relações. (FOUCAULT, 1995).

Conforme Foucault, o conceito de corpo e poder estão intimamente relacionados. Corpo entendido como qualquer coisa que é capaz de ser afetado e de afetar através do poder exercido. Nesse sentido, o corpo estaria imerso em relações de poder, sendo atravessado, marcado, falado e construído por relações, não podendo escapar delas e atuando através das mesmas. Por isso, o poder não é algo que está no exterior, mas uma parte constitutiva da pessoa. (FOUCAULT, 1999a)

Desta forma, a principal função desse poder é tornar os corpos maleáveis, e adestrá- los, tornando-os dóceis e moldáveis como forma do exercício do controle e dominação, tendo em vista que "em qualquer sociedade, o corpo está preso no interior de poderes muito apertados, que lhe impõem limitações, proibições ou obrigações". (FOUCAULT, 2004, p.126).

O poder, nesse sentido, circula nas relações através dos discursos e práticas. E, nessa perspectiva, o biopoder, conforme proposto por Foucault, seria um mecanismo de poder aplicado pelos estados capitalistas modernos, como forma de controlar as multidões. Através de diversos mecanismos de biopoder, o controle da população pode ser administrado como algo racional e alcançado por consenso, a título exemplificativo, cita-se os hábitos de saúde, as práticas reprodutivas, os comportamentos sexuais, dentre outros. Neste contexto, utilizando um léxico foucaultiano, os hospitais tornaram-se, uma das mais importantes "instituições disciplinares" de onde o biopoder é administrado.

Desta forma, onde se exerce o biopoder há uma extensa produção do saber. E, essa produção do saber científico sobre o corpo, se dá através da sua politização, passando este a 
ser um objeto de controle. A partir de tais perspectivas, as cesáreas eletivas funcionam como estratégias para que haja esse controle das massas.

\subsection{Cesáreas eletivas como estratégia da biopolítica}

A violência obstétrica está diretamente relacionada à história do parto, e se fez presente, sobretudo, após a inserção da prática obstétrica na medicina em que o parto deixou de ser um episódio natural, compartilhado apenas no seio familiar, para se tornar uma espécie de evento no ambiente hospitalar, prática dominada pela medicina e institucionalizada nos hospitais. Também conhecida como violência institucional na atenção obstétrica, a violência obstétrica caracteriza-se pela:

[...] violência cometida contra a mulher grávida, e sua família em serviços de saúde durante a assistência ao pré-natal, parto, pós-parto, cesárea e abortamento. Pode ser verbal, física, psicológica ou mesmo sexual e se expressa de diversas maneiras explícitas ou veladas. Como outras formas de violência contra a mulher, a violência obstétrica é fortemente condicionada por preconceitos de gênero. (CIELLO et al, 2012, p. 11).

A violência obstétrica corresponde a uma forma específica de violência de gênero, uma vez que há utilização arbitrária do saber por parte dos profissionais da saúde no controle dos corpos e da sexualidade das pacientes. Consoante Aguiar:

Estes maus tratos vividos pelas pacientes, na maioria das vezes, segundo alguns autores, encontram-se relacionados a práticas discriminatórias por parte dos profissionais, quanto a gênero, entrelaçados com discriminação de classe social e etnia, subjacentes à permanência de uma ideologia que naturaliza a condição social de reprodutora da mulher como seu destino biológico, e marca uma inferioridade física e moral da mulher que permite que seu corpo e sua sexualidade sejam objetos de controle da sociedade através da prática médica (2010, p. 15).

A institucionalização do parto abriu espaço para que se estabelecesse uma relação de poder/hierarquia entre o médico e a parturiente, potencializada pelas relações de gênero e poder enraizadas no meio social (CUNHA, 2012). Assim, a violência obstétrica no que diz respeito à medicalização do parto, se revela como uma imposição de valores patriarcais, principalmente relacionados ao caráter "defeituoso" do corpo feminino e à necessidade de controle de processos naturais pela medicina e ciência (HELMAN, 2009).

Retirada do seu papel de protagonista, a mulher se torna frágil, se submetendo cada vez mais a uma tecnologia que a infantiliza, fragiliza, descaracteriza e a 
violenta. O momento do parto e nascimento passa a ser encarado pelas mulheres como momento de medo e ameaça à integridade da vida, sendo muitas vezes indesejado por elas. A cesariana passa a ser uma possibilidade de fuga deste "sofrimento", de proteção da dignidade, já que o modelo de parto "normal" passa a ser considerado como degradante. Por outro lado, a cesariana é vista pelos profissionais de saúde, que se distanciam cada vez mais da arte de partejar, como modelo conveniente, pois troca a imprevisibilidade do parto normal por um planejamento taylorista das cesáreas, se apoiando no mito da tecnologia como sempre segura e eficaz (PASCHE; VILELA; MARTINS, 2010, p. 109).

Entre os anos de 2011 a 2012, a Escola Nacional de Saúde Pública da Fundação Oswaldo Cruz fez um levantamento pioneiro que mapeou a situação de nascimento em todas as regiões do Brasil. A pesquisa intitulada "Nascer no Brasil: Inquérito Nacional sobre Parto e Nascimento" (LEAL et al., 2012) coordenada pela fundação, foi realizada com a participação de renomados pesquisadores de várias instituições científicas, sendo a primeira a oferecer um panorama nacional sobre a situação de atenção ao parto e nascimento no Brasil. No total, 23.894 mulheres foram entrevistadas em maternidades públicas, privadas e mistas (maternidades privadas conveniadas ao Sistema Único de Saúde - SUS).

A pesquisa teve como objetivo averiguar os determinantes, magnitude e efeitos das intervenções obstétricas no parto, analisando a incidência de cesarianas desnecessárias; a motivação das mulheres em optar por determinada modalidade de parto; as complicações médicas durante o puerpério e período neonatal; além de descrever as estrutura das instituições hospitalares no que tange a qualificação dos recursos humanos, disponibilidade de insumos, equipamentos, medicamentos e unidade de terapia intensiva (UTI) para adultos e neonatos.

Constatou-se, a partir do estudo, a chamada “epidemia das cesáreas" no cenário do parto brasileiro, realizada em $52 \%$ dos nascimentos, sendo a problemática ainda mais crítica no setor privado, alcançando o patamar de $88 \%$ dos partos. Não houve quaisquer justificativas clínicas que justificassem esse percentual tão elevado. Estima-se que no Brasil, quase um milhão de mulheres, todos os anos, são submetidas a esse tipo de cirurgia sem indicação obstétrica adequada, expondo-se a riscos de morbidade e mortalidade, aumentando significativamente os recursos empregados na área de saúde e perdendo a oportunidade do protagonismo no momento do parto.

As cesarianas foram ainda frequentes nas adolescentes (42\%) que representaram $19 \%$ das mulheres participantes da pesquisa, destacando-se o perfil desfavorável destas com 
relação às adultas, uma vez que mais de dois terços pertenciam a classes sociais baixas (D e E), estavam em atraso escolar ou fora da escola, além de possuírem desvantagens quanto ao acesso ao pré-natal e número de consultas realizadas, fator que contribuiu significativamente para práticas associadas a violência obstétrica em virtude da vulnerabilidade latente da gestante que não realizou devidamente o acompanhamento prénatal.

Ademais, a maioria das adolescentes eram pretas e pardas (71\%), desigualdade que se refletiu também na fonte de pagamento do parto, tendo em vista que somente $4,5 \%$ pariram em estabelecimento privado. Entre as parturientes que optaram pelo parto via vaginal, observou-se a predominância de um modelo de atenção extremamente medicalizado, ignorando-se as evidências científicas disponíveis.

A maioria das mulheres foi submetida a intervenções excessivas e/ou procedimentos desnecessários, tais como: restrição ao leito, sem qualquer estímulo para caminhar; privação de alimentos durante o trabalho de parto; uso de medicamentos para acelerar as contrações (ocitocina sintética); uso da episiotomia ${ }^{6}$; parto em posição de litotomia ${ }^{7}$; uso da manobra de Kristeller ${ }^{8}$. Tais meios são hábitos rotineiros empregados pelos profissionais de saúde, não obstante serem práticas que violam contundentemente os direitos humanos das parturientes, ferindo suas integridades física, sexual e sobretudo psicológica, frequentemente caracterizando-se como condutas materializadoras da violência na atenção obstétrica.

Em outra pesquisa realizada pela Fiocruz (DIAS et al., 2008) envolvendo 487 puérperas observou-se que embora $70 \%$ das entrevistadas não relatassem preferência inicial pela cesariana, 90\% deram à luz por esse tipo de parto. Em $92 \%$ dos casos, a cirurgia foi realizada antes da mulher entrar em trabalho de parto, como acontece na maioria das vezes.

A relação entre a mortalidade materna e neonatal associada ao alto número de cirurgias cesarianas foi reconhecida no Relatório 2014 da PMNCH - Partnership for Maternal, Newborn and Child Health (Parceria para Saúde Materna, Neonatal e Infantil) da OMS, documento lançado no Fórum Mundial de 2014.

\footnotetext{
${ }^{6}$ Procedimento cirúrgico para aumentar a abertura do canal vaginal, cortando a entrada da vagina com uma tesoura ou bisturi, algumas vezes sem anestesia a fim de facilitar a saída do bebê no momento do parto.

${ }^{7}$ Posição onde o corpo está deitado com a face voltada para cima, joelho e quadril flexionado a $90^{\circ}$, expondo o períneo, conhecida também como posição ginecológica.

${ }^{8}$ Manobra na parte superior do útero, durante as contrações do parto, visando empurrar o nascituro em direção à pelve a fim de acelerar o trabalho de parto.
} 
Em 2015, a OMS preocupada com essa problemática, divulgou uma declaração sobre as taxas de cesárea, apontando o Brasil como líder mundial na prática e alertando acerca da epidemia eminente. Salienta-se que desde 1985, a recomendação da comunidade internacional de saúde considera que a taxa ideal de cesáreas deve ficar entre $10 \%$ e $15 \%$ de todos os partos realizados. No Brasil, mais da metade dos nascimentos são realizados por meio dessa modalidade de cirurgia, predominantemente na rede privada, conforme já ressaltado.

O sistema jurídico brasileiro não possui legislação específica sobre a temática "violência obstétrica", apenas abordagem genérica. Entretanto, existe o Projeto de Lei 7.633/2014, em tramitação no Congresso Nacional que dispõe sobre a humanização da assistência à mulher e ao neonato durante o ciclo gravídico-puerperal e dá outras providências. Elaborado pela Artemis ${ }^{9}$ que atua na defesa e promoção dos direitos das mulheres e assinado pelo deputado Jean Wyllys - PSOL/RJ, o projeto foca a questão do parto humanizado frente à prática indiscriminada de cirurgias cesarianas, visando mantê-las no percentual de $15 \%$ recomendado pela OMS.

O cenário brasileiro no que diz respeito ao parto é alarmante quando observado sob a ótica dos partos cesáreas. A partir de dados atuais $(2015)^{10}$, a OMS concluiu que as taxas de cesáreas são efetivas para salvar vidas de mães e crianças, quando indicadas ao caso e feitas em um ambiente seguro, mas faz alertas sobre os seus riscos.

Tais índices estão intrinsicamente relacionados a ideações culturais introjetadas a partir das quais o parto cesariano é visto como uma forma mais moderna e higiênica de parto, sendo uma escolha para as gestantes que têm maior poder aquisitivo, enquanto o parto normal é tido como feio, primitivo e sujo, realizado apenas com as que não possuem condições de arcar com os custos vultuosos de uma cesariana, conforme bem expressa Simone Dias, do Departamento de Saúde Pública da Universidade de São Paulo (USP).

Além disso, um dos fatores que mais influem para configurar esta problemática é o fato do parto normal ser um processo doloroso e arriscado no Brasil, gerando sofrimento à parturiente. Conforme ainda a pesquisadora, o parto normal com conotação violenta é

\footnotetext{
${ }^{9}$ Entidade de referência na implantação de políticas e serviços voltados para a melhoria da vida das mulheres, dando suporte ao setor público e privado na execução das mesmas.

${ }^{10}$ As cesarianas somam um índice de $84,6 \%$ na rede pública hospitalar e $40 \%$ na rede particular, segundo dados do Ministério da Saúde, fazendo do Brasil, líder mundial nesta modalidade de parto e dando ensejo à chamada "epidemia das cesáreas".
} 
constantemente utilizado para vender cesárea, desta forma, esta modalidade de parto se torna a melhor alternativa para escapar desse cenário comumente iatrogênico.

\begin{abstract}
No parto vaginal a violência da imposição de rotinas, da posição de parto e das interferências obstétricas desnecessárias perturbam e inibem o desencadeamento natural dos mecanismos fisiológicos do parto, que passa a ser sinônimo de patologia e de intervenção médica, transformando-se em uma experiência de terror, impotência, alienação e dor. Desta forma, não surpreende que as mulheres introjetem a cesárea como melhor forma de dar à luz, sem medo, sem risco e sem dor. (REHUNA, 1993, apud DINIZ, 2005, p. 631).
\end{abstract}

Assim, o excesso na realização de cesáreas no país pode estar ligado a fatores inerentes à violência obstétrica e ainda atrelado a questões sociais, culturais e econômicas.

Em geral, a cesariana é indicada quando o trabalho de parto é contraindicado ou quando não é provável que o parto vaginal seja alcançado com segurança, em intervalo de tempo necessário e seguro a fim de prevenir o desenvolvimento de morbidade fetal e/ou materna. Por si tratar de uma intervenção cirúrgica, a cesárea por si só, oferece riscos tanto à parturiente quanto ao neonato. Pode implicar em complicações maternas menores como episódios de febre ou perda maior do volume de sangue, até eventos maiores, tais como, lacerações acidentais de vísceras, infecções puerperais e acidentes anestésicos, razão pela qual as evidências médicas indicam que as taxas de mortalidade materna em decorrência de cesárea são até sete vezes maiores do que nos partos normais. (BRASIL, 2008).

A cesárea eletiva é aquela realizada sem necessidade clínica, podendo ser agendada e feita conforme a conveniência médica, antes mesmo do início do trabalho de parto, dissuadindo muitas vezes a mulher quanto à sua necessidade e também a coagindo. Conforme Maia:

\begin{abstract}
Diversas foram as causas relacionadas a esse evento: [...] medo, por parte das mulheres, da dor do parto normal; crença, por parte das mulheres e dos médicos, de que o parto vaginal afrouxa os músculos da vagina e interfere na satisfação sexual; crença de que o parto vaginal é mais arriscado para o bebê do que uma cesárea; conveniência (hora marcada) e economia de tempo para o médico; falta de qualificação do médico para o parto normal; pré-natal incapaz de preparar para o parto; atendimento centrado no médico, e não em equipes multidisciplinares que incluam obstetrizes; $[\ldots]$ a associação entre parto vaginal e imprevisibilidade, esta vista como algo negativo, e entre parto cesáreo e segurança. (2008, p. 38).
\end{abstract}

Em virtude da falta de informações, as parturientes ficam extremamente vulneráveis às indicações de cesáreas, submetendo-se, na maioria dos casos, a uma cirurgia 
de grande porte com riscos e complicações. Nesse contexto, as cirurgias cesarianas tornaram-se práticas naturalizadas, transformando o corpo feminino em máquina (força de produção), a fim de controlar as massas. Desta forma,

O parto passa a ser entendido como uma linha de montagem, nos moldes tayloristas, onde seriam produzidos humanos. A mulher deixa de ser a protagonista do próprio parto, que agora é comandado pelos médicos. Os saberes femininos relacionados à gestação e parto são rechaçados em favor dos saberes médico-científicos. Parteiras e comadres, que assistiam parturientes baseadas em saberes construídos pela experiência própria e pela tradição, são proibidas de partejar. O fórcepis permite a intervenção masculina e se torna instrumento de um novo paradigma do parto, agora entendido como um evento patológico e que deve ser controlado pelo médico homem. O parto assistido por parteiras passa a ser visto como sinônimo de atraso e rusticidade, enquanto o parto medicalizado é associado à civilidade. (CARVALHO, 2013, p. 04).

Diante de tais apontamentos, a profissão médica segundo Foucault (1995) exerce um poder sem controle sobre os corpos das pessoas, sua saúde, vida e morte. Esse poder médico se baseia na autoridade cultural e moral que a profissão médica exerce em nossa sociedade. Para Foucault (1999a), o discurso daquele que ordena a sociedade é sempre o discurso daquele que detém o saber. Assim, o saber produz verdades que se instalam e se revelam nas práticas discursivas. Desta forma,

\begin{abstract}
$\mathrm{Na}$ posição de doutores de um saber, sobre um outro que é objeto, médicos destronam a posição terapêutica para ocupar um lugar que nos ensina como devemos viver. Aqui, constata-se de maneira inteligível, o quanto o saber médico se articula ao poder disciplinar e normalizador. A ordem médica, assim compreendida articulada à microfísica do saber e poder, com seu olhar focado na doença e não na pessoa do doente, implica uma recusa e desqualificação da subjetividade e singularidade de cada fato clínico. (TAVIRA, 2014, p. 1).
\end{abstract}

Assim, o discurso médico é concebido como o discurso da verdade e seus profissionais aparecem como uma das autoridades mais importantes do nosso tempo. Isto tem consequências vitais, porque o discurso médico assume um poder institucional privilegiado, além da legitimação social para administrar e governar a vida.

Sob esse aspecto, um clássico livro denominado "Obstetrícia" de Jorge de Rezende postulado que:

A velha arte dos partos transfigurou-se, e tendo-se despojado da operatória de arrancamento, seu outrora campo único, limitou os atos extrativos, disciplinou-os e deu-lhes suavidade. A espera resignada e fatalista do parto vaginal pôde ser derrogada com o desenvolvimento da fisiopatologia da contração uterina que permitiu governá-lo, encurtar-lhe as fases, monitorá-lo, induzi-lo; mediante o 
aperfeiçoamento da anestesiologia, tornando-o indolor, e, através dos préstimos da operação cesariana, cristalizada em técnica de simplicidade extrema (REZENDE, 2006, p.2, grifo nosso).

Imperioso registrar, como o discurso justificador proposto por Rezende pode ser análogo aos apontamentos propostos por Foucault no que tange a disciplina dos corpos. Nesse sentido, o parto vaginal passa a ter conotação de atrasado, perigoso, sujo, dolorido, e transformaram o parto cesariana em estéril, limpo, higiênico, com procedimento rápido e simples, indolor, e isso pode plenamente ser percebido através dos discursos médicos e a exposição midiática, tornando assim os hábitos cada vez mais automáticos.

Desta forma, usa-se a disciplina para a fabricação de um sujeito que atenda a esses requisitos básicos, conforme se depreende dos depoimentos ${ }^{11}$ expostos abaixo:

[...] é um procedimento seguro, o bebê já está maduro, não tem com o que se preocupar, é muito mais cômodo pra família, mais fácil, melhor para aproveitar a licença-paternidade, você não vai sentir dor e ainda vai continuar apertadinha para seu marido.

Meu obstetra, que era meu médico há 9 anos, me disse que meu bebê não nasceria de parto normal porque meu colo de útero estava ainda grosso e ela não estava encaixada com 39 semanas de gestação. Marcou a cesárea para dali a alguns dias. Procurei outro profissional e tive meu parto normal com 41 semanas. (Eleonora Moraes, atendida através de plano de saúde em Ribeirão Preto - SP).

O médico diz que não era pra eu sofrer. Se eu quisesse fazer a cesárea, ele faria. 38 semanas o bebê já está pronto. (Thais Saito, atendida através de plano de saúde no Hospital Santa Joana em São Paulo - SP, foi submetida à cesárea).

Meu médico disse que eu poderia sofrer mais no parto normal. Como eu tinha medo de ficar sentindo dor, ele conseguiu me convencer a fazer a cesárea. (Patrícia Reis França, em entrevista para a Folha de São Paulo do dia 20 de novembro de 2011).

Quando completei 40 semanas, o obstetra solicitou um ultrassom para avaliar se ainda dava para esperar que eu entrasse em trabalho de parto espontaneamente. $\mathrm{O}$ resultado do exame foi ótimo, boa quantidade de líquido, placenta grau II, boa vitalidade fetal. Porém, meu médico me indicou uma cesárea para o dia seguinte alegando que se o bebê não tinha encaixado ainda, ele não encaixaria mais. Fui para casa chorando. Meu marido tentou me consolar dizendo que poderíamos consultar outro médico, já que o exame dizia que estava tudo bem. Mas ir para qual médico? Ainda liguei para desmarcar a cirurgia e o médico limitou-se a dizer que eu deveria tomar um calmante e que eu não devia colocar a vida do meu filho em risco adiando essa cirurgia. (Socorro Moreira, atendida através de plano de saúde em Fortaleza-CE).

Meu médico indicou a cesárea porque o cordão estava enrolado no pescoço. Ele pediu para que a cirurgia fosse marcada para a quarta-feira de manhã, pois ele só

\footnotetext{
${ }^{11}$ Depoimentos reais extraídos do Dossiê "Parirás com dor" elaborado pela Rede Parto do Princípio para a CPMI da Violência Contra as Mulheres. Grifo nosso
} 
tinha esse horário disponível e o parto normal poderia matar meu bebê. Eu nunca iria desejar a morte do meu filho. (E.S.S. de 30 anos, atendida através de plano de saúde em Vitória - ES).

Diante da falta de informações, as mulheres tornam-se extremamente vulneráveis às indicações de cesáreas questionáveis, submetendo-se a uma cirurgia de grande porte com riscos e complicações para mãe e bebê. (CIELLO et al, 2012). A vida, nesse sentido, tornou- se objeto de poder que:

[...] regula a vida social por dentro, acompanhado-a, interpretando-a, absorvendoa e a rearticulando. $\mathrm{O}$ poder só pode adquirir comando efetivo sobre a vida total da população quando se torna função integral, vital, que todos os indivíduos abraçam e reativam por sua própria vontade. A função mais elevada desse poder é envolver a vida totalmente, e sua tarefa primordial é administrá-la. O biopoder, portanto, se refere a uma situação na qual o que está diretamente em jogo no poder é a produção e a reprodução da própria vida. (NEGRI, HARDT, 2001, p 43).

Os discursos produzidos docilizaram o corpo feminino, através de técnicas de dominação características do biopoder e corroboram para que grande parte das mulheres tenha preferência pelo parto cesárea. As pacientes, adoram a ideia de um parto sem dor antes e durante (ainda que um pouco mais dolorido depois), com data marcada e ainda a vantagem de preservar o aparelho genital. (CIELLO et al, 2012).

Ademais, a publicidade e o discurso médico fazem uma clara alusão à cesárea como opção mais segura no parto e influem nessa decisão, conforme se depreende do excerto $^{12}$ : “A cesariana é a evolução do parto. É rápida e não causa trauma para a mulher"13.

As cesáreas eletivas são divulgadas sem restrição pela mídia brasileira e os discursos produzidos a elegem como a opção mais cômoda para a parturiente e toda sua família, podendo-se contar com serviços previamente agendados que podem ser atrelados à cirurgia, tais como: manicure, pedicure, escova, maquiagem, serviços de fotografia e filmagem e, mais recentemente, os serviços de buffet com decoração para comemoração antes, durante e depois da cesárea; além da transmissão simultânea do nascimento através de câmeras que ficam dentro do centro cirúrgico para auditórios repleto de familiares. (CIELLO et al, 2012).

Nesse sentido, no discurso das mulheres que preferem parto cesariana:

\footnotetext{
12 Extraídos do Dossiê “Parirás com dor” elaborado pela Rede Parto do Princípio para a CPMI da Violência Contra as Mulheres.

${ }^{13}$ Fabio Leal, presidente da Associação de Ginecologistas e Obstetras do Espírito Santo em entrevista a Tribuna, 23 de fevereiro de 2012, Vitória - ES.
} 


\begin{abstract}
O parto vaginal aparece como um risco para a saúde, em especial para o recémnascido. Assim, a decisão pela via de nascimento é pautada em avaliações sobre possíveis riscos. A cirurgia cesárea é percebida como mais segura [...] Há uma ideia de responsabilidade materna para com a saúde do feto que se junta com a dificuldade do parto vaginal e despreparo do corpo feminino para parir. A responsabilidade moral com a própria saúde e a do bebê em especial, somando-se à constituição do parto vaginal como um risco acaba por justificar a realização da cesárea, já que, em função da confiança que se construiu na tecnologia, há pouca preocupação com possíveis iatrogenias. Desde o pré-natal, inúmeras intervenções são realizadas para garantir a saúde perfeita da mãe e do bebê. [...] As mulheres alegam precisar racionalizar e organizar seu tempo e uma das principais vantagens da cesariana é a possibilidade de dia e hora marcada. A necessidade do controle do tempo e a lógica do planejamento aparecem desde a concepção, que geralmente é planejada. As questões conjugais, familiares, profissionais e financeiras são pensadas antes da gestação e no momento do nascimento pelas mulheres, na perspectiva da possibilidade de controle sobre o tempo, o corpo e a vida. (RISCADO; BONAN; BARBOSA, [2015 ou 2016], p. 6).
\end{abstract}

Diante de tais apontamentos, percebe-se um "aprisionamento dos corpos" das parturientes, disciplinando-os. Através de discursos, muitas vezes falaciosos, as mulheres se enveredam a um parto medicalizado, tornando-se vulneráveis diante das práticas médicas.

\title{
3 CONSIDERAÇÕES FINAIS
}

A imposição de intervenções médicas desnecessárias que muitas vezes são danosas, prejudicam tanto a integridade física quanto psíquica da mulher, desrespeitando a sua autonomia. Segundo a OMS, muitas das intervenções que são aplicadas rotineiramente são consideradas como um fator de risco tanto para a mulher quanto para o neonato. As crenças e os preconceitos no que concerne à sexualidade e saúde das mulheres em uma sociedade tipicamente patriarcal contribuem sobremaneira diante da forma como elas são vistas e (des)tratadas pelos profissionais.

Nesse sentido, a crescente prática da cesárea entre as mulheres faz parte de um contexto sociocultural, econômico e político em que se valoriza a ideia de controle tecnológico do corpo e da vida, expressando a noção de biopoder proposta por Foucault. (FOUCAULT, 2009; ROSE, 2013).

Essa atuação do biopoder sobre o corpo feminino constrói uma história que nega a autonomia feminina, transformando-as em sujeitos anônimos, incapazes de conduzir livremente suas decisões. Nesse sentido, a epidemia de cesáreas aparece como exemplo paradigmático da excessiva intervenção tecnológica sobre corpo e dinâmicas das mulheres.

O contexto sociocultural da mulher da contemporaneidade imprime novas relações 
de gênero, havendo uma necessidade de controle excessivo que exige uma constante atenção com a saúde, a estética, o desempenho sexual e social e a produtividade.

O aumento considerável nos índices de cirurgias cesarianas no Brasil, transforma o momento do parto em um processo rotineiro e muitas vezes sem indicação médica, medicalizando-o. Percebe-se que a cultura das cesarianas é construída a partir de discursos e produção de saberes nas práticas obstétricas, a saber: o parto normal como algo sujo, primitivo, perigoso, dolorido com grandes riscos, em detrimento da cesariana que é rápida, cômoda e indolor ${ }^{14}$.

Evidencia-se, assim, um processo de "coisificação" da mulher, na medida em que ela deixa de ser protagonista do processo de parto e passa a ser apenas um "objeto" de intervenção médica. (GOMES; KUNZLER, 2015, p. 2)

No entanto, importante salientar que a cesárea não pode ser vista de modo indiscutível como sinônimo de violência obstétrica, mas pode ser considerada uma prática associada ao fenômeno quando é realizada sem uma real necessidade, ou ainda quando as mulheres passam por um processo de ameaça, coerção e convencimento através do qual o médico impõe sua vontade, desrespeitando a autonomia da gestante . Além disso, diante da ausência de informação adequada, as parturientes ficam extremamente vulneráveis às indicações de cesáreas, submetendo-se, na maioria dos casos, a uma cirurgia de grande porte com riscos e complicações, funcionando como uma estratégia da biopolítica para o controle das massas, conforme os fundamentos expostos sob uma perspectiva foucaultiana.

Sob essa perpectiva, a medicalização do corpo das mulheres passou a acontecer em um contexto maior de medicalização da vida privada, através de mecanismos de biopoder que visam o controle populacional, a disciplinarização da força de trabalho e a higienização dos espaços e das relações sociais. (FOUCAULT, 2009).

Além disso, o discurso produzido através da valorização da figura materna na cultura cristã corrobora para que as parturientes imputem sobre si, toda responsabilidade caso algo dê errado no momento do parto. Assim, da mesma forma como um relacionamento feliz e a manutenção da família é uma responsabilidade atribuída as

\footnotetext{
${ }^{14}$ Diante dessa problemática, o Conselho Federal de Medicina (CFM) implantou a Resolução 2144/2016 que entrou em vigor no dia 22 de junho de 2016 estabelecendo novos critérios para realização das cirurgias cesarianas que com escopo de garantir a segurança do feto somente poderá ser realizada a partir da $39^{\mathrm{a}}$ semana de gestação, com o devido registro em prontuário. Conforme a exposição de motivos listados pelo CFM consta como o principal: o respeito a autonomia da parturiente implicando uma reconfiguração na relação médicopaciente. Ao ser bem informada, a mulher deve decidir com o médico as melhores opções de tratamento, reconhecendo-se à paciente, o direito de tomar decisões conscientes, baseadas na melhor evidência científica.
}

Revista de Gênero, Sexualidade e Direito | e-ISSN: 2525-9849 | Belém | v. 5 | n. 2 | p. 74 - 95 | Jul/Dez. 2019. 
mulheres, o sucesso de um parto bem-sucedido também o é. A sociedade induz as mulheres a se transformarem em mártires, sendo elas atingidas prioritariamente pela medicalização de seus corpos. Nesta senda, "A necessidade de controlar as populações, aliada ao fato de a reprodução ser focalizada na mulher, transformou a questão demográfica em problema de natureza ginecológica e obstétrica, e permitiu a apropriação do corpo feminino como objeto de saber" (COSTA et.al., 2006, p.368-369).

Nesse sentido, na contemporaneidade emergem vários discursos produzidos com o escopo de cuidado e proteção do corpo feminino, politizando a maternidade e deslocando a mulher da posição de sujeito à objeto durante o parto, transformando-a em um corpo passivo, gerando a dificuldade em reconhecer determinadas práticas intervencionistas como violência obstétrica.

\section{REFERÊNCIAS}

AGAMBEM, Giorgi. O amigo \& O que é um o dispositivo. Chapecó, SC: Argos, 2015.

AGUIAR, Janaína Marques de. Violência institucional em maternidades públicas: hostilidade ao invés de acolhimento como uma questão de gênero. Disponível em: <http://www.apublica.org/wp-content/uploads/2013/03/JanainaMAguiar.pdf >. Acesso em: 02 nov. 2015.

ARGENTINA. Ley 26.485, de 11 de marzo de 2009. Ley de protección integral para prevenir, sancionar y erradicar la violencia contra las mujeres en los ámbitos en que desarrollen sus relaciones interpersonales. Disponível em:

<http://www.osim.com.ar/osim/alzalavoz/Ley_de_Proteccion_Integral_de_Mujeres_Argen tin a.pdf $>$. Acesso em: 02 nov. 2015.

CARVALHO, Clarissa Sousa de. Violência obstétrica: etnografia de uma comunidade no Facebook. 2013. Disponível em: <http://eventos.livera.com.br/trabalho/981018971_01_07_2015_03-55-12_2788.PDF>

CIELLO, Cariny et al. Parto do princípio. Mulheres em Rede pela Maternidade Ativa. Dossiê da Violência Obstétrica "Parirás com dor". 2012. Disponível em: <https://www.senado.gov.br/comissoes/documentos/SSCEPI/DOC\%20VCM\%20367.pdf $>$. Acesso em: 10 dez. 2015.

COSTA, Tonia et. al. Naturalização e medicalização do corpo feminino: o controle social por meio da reprodução. Interface - Comunicação, Saúde, Educação,Botucatu, v.10, n.20, p.363-380, jul-dez 2006.

BRASIL. Decreto no 1.256 , de 29 de setembro de 1994. Promulga a Convenção 
Interamericana para Prevenir, Punir e Erradicar a Violência contra a Mulher, concluída em Belém do Pará, em 9 de junho de 1994. Diário Oficial da União, Brasília, DF, 2 ago. 1996. Seção 1, p. 15.

. Agência Nacional de Saúde Suplementar. O modelo de atenção obstétrica no setor de Saúde Suplementar no Brasil: cenários e perspectivas. Rio de Janeiro: ANS, 2008.

. Projeto de Lei 7.633/2014. Dispõe sobre a humanização da assistência à mulher e ao neonato durante o ciclo gravídico-puerperal e dá outras providências. Disponível em: < http://www.camara.gov.br/proposicoesWeb/prop_mostrarintegra? codteor $=1257785 \&$ filename $=P L+7633 / 2014$. Acesso em: 10 dez. 2015.

CHAZAN, Lilian Krakowski. Meio quilo de gente: um estudo antropológico sobre ultra- som obstétrico. Rio de Janeiro: Editora Fiocruz, 2007.

CUNHA, Eliana. Violência no parto em Minas Gerais. Denúncia à Comissão de Direitos humanos da Assembleia Legislativa. Belo Horizonte, 2012. Disponível em: <http://www.redehumanizasus.net/sites/default/files/violencia_no_parto_em_minas_gerais__versao_final.pdf >. Acesso em: 11 mai. 2017.

DIAS, Marcos Augusto Bastos et al. Trajetória das mulheres na definição pelo parto cesáreo: estudo de caso em duas unidades do sistema de saúde suplementar do estado do Rio de Janeiro. Ciência \& Saúde Coletiva, 13(5):1521-1534, 2008. Disponível em: <http://www.scielo.br/pdf/csc/v13n5/17.pdf>. Acesso em: 24 mar. 2017.

DINIZ, Carmen Simone Grilo. Humanização da assistência ao parto no Brasil: os muitos sentidos de um movimento. Ciênc. saúde coletiva vol.10, nº 3 , Rio de Janeiro July/Sept. 2005. Disponível em: < http://www.scielo.br/pdf/ csc/v10n3/a19v10 n3.pdf>. Acesso em: 21 ago. 2016.

DINIZ, Francisco Rômulo Alves; OLIVEIRA, Almeida Alves de. Foucault: do poder disciplinar ao biopoder. Scientia vol. 2, no 3, p. 01 - 217, nov. 2013/jun.2014. Disponível em: <http://www.faculdade.flucianofeijao.com.br/site_novo/scientia/ servico/pdfs/VOL2_N3/FRANCISCOROMULOALVESDINIZ.pdf >. Acesso em: 21 ago. 2016.

FOUCAULT, Michel. A ordem do discurso. Edições Loyola, São Paulo, 1999a. Disponível em: <http://www.campusbreves.ufpa.br/ARQUIVOS/FACLETRAS/

SANDRAJOB/foucault-m-a-ordem-do-discurso.pdf>. Acesso em: 21 ago. 2016.

Em defesa da sociedade. Trad. Mana Ermantina Galvão - São Paulo: Martins fontes, $1999 \mathrm{~b}$. 
História da sexualidade 1: a vontade de saber. 19. ed. Rio de Janeiro: Graal, 2009.

. Microfísica do poder. São Paulo: Edições Graal, 2008.

Os corpos dóceis. In: Vigiar e punir: nascimento da prisão. $29^{a}$ ed. Tradução de Raquel Ramalhete. Petrópolis, RJ: Vozes, 2004.

O Sujeito e o poder. In: Rabinow P, Dreyfus HL, Foucault M. Uma

trajetória filosófica para além do estruturalismo e da hermenêutica. Rio de Janeiro:

Forense Universitária; 1995.

Vigiar e Punir. Trad. Raquel Ramalhete. 38ª ed. Petrópolis - RJ: Vozes, 2010.

GOMES, Paulo Ricardo Favarin; KUNZLER, Ilse Maria. Violência obstétrica e relações de poder no parto. Disponível em: <https://www.revistas.unijui.edu.br/index.php/salao conhecimento/article/view/5086/4267>. Acesso em: 21 ago. 2016.

HELMAN, Cecil G. Cultura, Saúde e Doença. Tradução Ane Rose Bolner. 5. ed. Porto Alegre: Artes Médicas, 2009.

KÊNIA, Míriam. O nascimento biopolítico: convocações dos dispositivos de mídia em prol da cesariana e do medo do parto. Dissertação (Mestrado). Pontifícia Universidade Católica de São Paulo, 2016. Disponível em: < https://tede2.pucsp.br/bitstream/handle/19112/2/M\%C3\%

ADriam\%20K\%C3\%AAnia.pdf>. Acesso em: 12 ago. 2019.

LEAL, Maria do Carmo et al. Nascer no Brasil: Inquérito Nacional sobre Parto e Nascimento. Rio de Janeiro: ENSP/Fiocruz, 2012. Disponível em: $<$ http://www.ensp.fiocruz.br/portalensp/informe/site/arquivos/anexos/nascerweb.pdf >. Acesso em: 15 nov. 2015.

MACHADO, Roberto. Foucault, a ciência e o saber. $4^{\mathrm{a}}$ ed. Rio de Janeiro: Jorge Zahar, 2009.

MAIA, Mônica Bara. Humanização do parto: política pública, comportamento organizacional e ethos profissional. Rio de Janeiro: Fiocruz, 2008. Disponível em: < http://www.biblioteca.pucminas.br/teses/CiencSociais_MaiaMB_1.pdf >. Acesso em: 13 out. 2015.

MARINHO, Maykon dos Santos; REIS, Luciana Araújo dos. O panoptismo como dispositivo de controle social: um breve estudo à luz do pensamento de Michel Foucault. 2014. Disponível em: <http://pergaminho.unipam.edu.br/documents/43440/ 599489/O+panoptismo+como+dispositivo+de++controle+social+-+um+breve+ estudo++\% C3\%A0\%20luz+do+pensamento+de+Michel+Foucault.pdf $>$. Acesso em: 21 ago. 2016.

NEGRI, Antonio; HARDT, Michael. Império. Rio de Janeiro/ São Paulo: Ed. Record, 2001. 
ORGANIZAÇÃO MUNDIAL DE SAÚDE. Declaração da OMS sobre Taxas de Cesáreas. 2015. Disponível em: <http://apps.who.int/iris/bitstream/10665/161442/3/ WHO_RHR_15.02_por.pdf>. Acesso em: 04 nov. 2015.

Prevenção e eliminação de abusos, desrespeito e maus-tratos durante o parto em instituições de saúde. 2014. Disponível em: <http://apps.who.int/iris/bitstream/10665/134588/3/WHO_RHR_14.23 _por.pdf>. Acesso em: 04 nov. 2015.

Relatório mundial sobre violência e saúde. Genebra, 2002. Disponível em: <https://www.opas.org.br/wp-content/uploads/2015/09/relatorio-mundialviolencia- saude.pdf $>$. Acesso em: 04 nov. 2015.

PAES, Fabiana Dal'Mas Rocha. Estado tem o dever de prevenir e punir a violência obstétrica. 2015. Disponível em: < http://www.conjur.com.br/2015-dez07/mp-debate- estado-dever-dever-prevenir-punir-violencia-obstetrica>. Acesso em: 10 dez. 2015.

PASCHE, Dário Frederico; VILELA, Maria Esther de Albuquerque; MARTINS, Cátia Paranhos. Humanização da atenção ao parto e nascimento no Brasil: pressuposto para uma nova ética na gestão e no cuidado. Revista Tempus Actas Saúde Coletiva, Brasília, v. 4, n. 4, 2010.

REZENDE, Jorge de. Operação cesariana. Rio de Janeiro: Guanabara Koogan. 3.ed. 2006.

RISCADO, Liana Carvalho Riscado; BONAN, Claudia; BARBOSA, Regina Helena Simões Barbosa. A prática da cesárea no setor privado de saúde: um estudo a partir da análise das práticas discursivas de mulheres. Disponível em:

<http://webcache.googleusercontent.com/search?q=cache:V28M1eJLgj4J:ciem.ucr.ac.cr/al as/docs/GT11/A\%2520pr\%25C3\%25A1tica\%2520da\%2520ces\%25C3\%25A1rea\%2520no $\% 2520$ setor $\% 2520$ privado $\% 2520 \mathrm{de} \% 2520$ sa $\% 25 \mathrm{C} 3 \% 25 \mathrm{BAde} \% 2520$ um $\% 2520$ estudo $\% 25$ 20a\%2520partir\%2520da\%2520an\%25C3\%25A1 lise $\% 2520$ das $\% 2520$ pr\%25C3\%25A1tica s\%2520discursivas\%2520de\%2520mulheres.doc $+\& \mathrm{~cd}=1 \& \mathrm{hl}=\mathrm{pt}-\mathrm{BR} \& \mathrm{ct}=\mathrm{clnk} \& \mathrm{gl}=\mathrm{br}>$. Acesso em: 21 ago. 2016.

ROSE, N. A política da própria vida. Biomedicina, poder e subjetividade no século XXI. $1^{a}$ Ed. 2013. São Paulo: Paulus.

SOUSA, Valéria. Violência obstétrica: nota técnica. Considerações sobre a violação de direitos humanos das mulheres no parto, puerpério e abortamento. São Paulo: Artemis, 2015.

TAVIRA, Larissa V. O nascimento da clínica em Foucault - um poder-saber sobre a 
vida. (Em)Cena - Saúde Mental em Movimento. Palmas: Ceulp/Ulbra, 2014. 